\title{
Assessment of a universal preprocedural screening program for coronavirus disease 2019 (COVID-19)
}

\author{
Lana Dbeibo MD ${ }^{1,2}$ (1), Kari Kuebler RN, BSN², Alyson Keen MSN, RN, ACNS-BC², Annie George BSN, RN², \\ Kristen Kelley MPH, RN, CIC, FAPIC ${ }^{2}$, Josh Sadowski BS², Laura Basham MSN, RN, AGCNS-BC², \\ Terrie Beeson MSN, RN, CCRN, ACNS-BC ${ }^{2}$, C. Max Schmidt MD, PhD, MBA, DABS ${ }^{1,2}$, Cole Beeler MD ${ }^{1,2}$ and \\ Douglas Webb MD $\mathrm{MD}^{1,2}$ \\ ${ }^{1}$ Indiana University School of Medicine, Indianapolis, Indiana and ${ }^{2}$ Indiana University Health Adult Academic Health Center, Indianapolis, Indiana
}

To the Editor-The novel coronavirus 2019 (COVID-19) has caused a global pandemic, placing an unprecedented strain on the US healthcare system. On March 12, 2020, to preserve the safety of hospital staff and patients during the pandemic, the US Department of Health and Human Services and the American College of Surgeons issued a guidance for hospitals and healthcare systems to postpone elective procedures. ${ }^{2}$ Similar guidance followed from the US Surgeon General and the US Centers for Medicare and Medicaid Services, operationalized by individual states. $^{3,4}$ Decreased surgical capacity from COVID-19 has affected healthcare economic and patient outcomes. As a frame of reference, deferred elective surgical activity in 2003 during the severe acute respiratory syndrome (SARS) pandemic resulted in an estimated $\$ 32.1$ million in direct cost to hospitals in the Toronto and greater Toronto are ${ }^{5}$ and uninteded consequences, such as seriously ill patients not seeking care. ${ }^{6}$

As states have gradually allowed elective procedures to resume in the United States, healthcare organizations have been responsible for mitigating the spread of severe acute respiratory coronavirus virus 2 (SARS-CoV-2), the virus that causes COVID-19. In particular, although the importance of screening all patients with and without symptoms has been recognized, some still question the value of universal screening given economic and operational considerations.

In this study, we aimed (1) to determine the value of universal preprocedural screening for a representative academic health center and (2) to determine the safety of resuming elective procedures using the volume of asymptomatic positive screens.

\section{Methods}

This descriptive study included patients undergoing procedures in the operating room, procedures in the cardiac catheterization lab, and endoscopies at a public, adult, academic, tertiary-care, referral center in Indiana. Patients were included in the sample if they had had a COVID-19 screen performed within 96 hours of a scheduled elective procedure or within 24 hours after an emergent procedure. Patients were classified as symptomatic if they met either of the following criteria: (1) screen performed due to presence of COVID-19 symptoms $^{7}$ or (2) documentation of COVID-19

Author for correspondence: Lana Dbeibo, E-mail: ldbeibo@iu.edu

Cite this article: Dbeibo L, et al. (2022). Assessment of a universal preprocedural screening program for coronavirus disease 2019 (COVID-19). Infection Control \& Hospital Epidemiology, 43: 546-548, https://doi.org/10.1017/ice.2021.40 symptoms in the electronic medical record at the time of the test. Patients with a positive screen that did not meet symptomatic criteria were classified as asymptomatic.

A preprocedural screening program was implemented on May 4,2020 , recommending screening within 96 hours of a scheduled procedure. Screening involved a real-time polymerase chain reaction (RT-PCR) test collected by oropharyngeal and nasopharyngeal swab. Patients with a positive or pending result were rescheduled, unless considered emergent. In the event of an emergent case, COVID-19 isolation precautions were implemented. Standard precautions were followed for patients with a negative screen unless the patient had symptoms and the proceduralist had concern for a false-negative screen.

An infection prevention (IP) data analyst generated a report from the electronic health record for patients undergoing procedures for a 6-week period of time from May 4 through June 14, 2020. An IP and a registered nurse (RN) independently conducted manual chart reviews to verify the inclusion criteria and the screening result and to categorize patients with positive screens as symptomatic or asymptomatic. The IP and RN then cross verified the manual chart reviews to reach consensus, and any discrepancies were resolved by consultation with a third reviewer (an infectious disease physician). Patients meeting symptomatic criteria were excluded from the analysis. Descriptive statistics were used to calculate frequencies and percentages for the included sample of patients.

\section{Results}

The initial sample included 2,194 patients, comprising 46 positive and 2,148 negative screens. Among the 46 positive screens, 29 patients met symptomatic criteria and were excluded from the sample, leaving a final sample of 2,165 patients. The remaining 17 patients were verified as asymptomatic positive screens, resulting in a rate of $0.79 \%$ (17 of 2,165$)$. Trauma service patients had the highest positive incidence at $23.5 \%$. Demographic data for the 2,165 patients included in the final sample are provided in Table 1.

\section{Discussion}

Our study showed a low prevalence of positive asymptomatic COVID-19 screens $(0.79 \%)$, a rate similar to a preprocedural screening program in the state of Washington $(0.8 \%),{ }^{8}$ substantially lower than the 5\%-80\% range reported in an international review. ${ }^{9}$ Notably, however, Indiana was on a downward trend

(c) The Author(s), 2021. Published by Cambridge University Press on behalf of The Society for Healthcare Epidemiology of America. This is an Open Access article, distributed under the terms of the Creative Commons Attribution licence (http://creativecommons.org/licenses/by/4.0/), which permits unrestricted re-use, distribution, and reproduction in any medium, provided the original work is properly cited. 
Table 1. Sample Demographics

\begin{tabular}{|c|c|c|c|}
\hline Characteristic & $\begin{array}{l}\text { Asymptomatic } \\
\text { Positive No. (\%) }\end{array}$ & Negative No. (\%) & Total No. $(\%)$ \\
\hline Total & $17(0.79)$ & $2,148(99.21 \%)$ & 2,165 \\
\hline \multicolumn{4}{|l|}{ Age, $y$} \\
\hline$<18$ & & $20(0.93)$ & $20(0.92)$ \\
\hline $18-44$ & $11(64.71)$ & $587(27.33)$ & $598(27.62)$ \\
\hline $45-64$ & $5(29.41)$ & $842(39.20)$ & $847(39.12)$ \\
\hline $65-74$ & $1(5.88)$ & $438(20.39)$ & $439(20.28)$ \\
\hline $75+$ & & $261(12.15)$ & $261(12.06)$ \\
\hline \multicolumn{4}{|l|}{ Gender } \\
\hline Male & $9(52.94)$ & $1,089(50.70)$ & $1,098(50.72)$ \\
\hline Female & $8(47.06)$ & $1,059(49.30)$ & $1,067(49.28)$ \\
\hline \multicolumn{4}{|l|}{ Race/Ethnicity } \\
\hline Hispanic & $2(11.76)$ & $70(3.26)$ & $72(3.33)$ \\
\hline Non-Hispanic (NH) White & $6(35.29)$ & $1,664(77.47)$ & $1,670(77.14)$ \\
\hline NH Black/African American & $9(52.94)$ & $328(15.27)$ & $337(15.57)$ \\
\hline NH American Indian/Alaska Native & & $1(0.05)$ & $1(0.05)$ \\
\hline NH Asian & & $23(1.07)$ & $23(1.06)$ \\
\hline NH Native Hawaiian/other Pacific Island & & $1(0.05)$ & $1(0.05)$ \\
\hline Not specified & & $61(2.84)$ & $61(2.82)$ \\
\hline \multicolumn{4}{|l|}{ Service line } \\
\hline Anesthesia & $1(5.88)$ & $4(0.19)$ & $5(0.23)$ \\
\hline Cardiology & $3(17.56)$ & $18(0.84)$ & $21(0.97)$ \\
\hline Cardiovascular & $1(5.88)$ & $61(2.84)$ & $62(2.86)$ \\
\hline Ear, nose, and throat & & $103(4.80)$ & $103(4.76)$ \\
\hline Gastroenterology & $2(11.76)$ & $294(13.69)$ & $296(13.67)$ \\
\hline Neurosurgery & $1(5.88)$ & $125(5.82)$ & $126(5.82)$ \\
\hline Obstetrics \& gynecology & $2(11.76)$ & $148(6.89)$ & $150(6.93)$ \\
\hline Ophthalmology & & $2(0.09)$ & $2(0.09)$ \\
\hline Oral maxillofacial surgery \& dentistry & & $23(1.07)$ & $23(1.06)$ \\
\hline Orthopedics & $2(11.76)$ & $281(13.08)$ & $283(13.07)$ \\
\hline Peripheral vascular & & $74(3.45)$ & $74(3.42)$ \\
\hline Plastic surgery & $2(11.76)$ & $38(1.77)$ & $40(1.85)$ \\
\hline Podiatry & & $5(0.23)$ & $5(0.23)$ \\
\hline Pulmonology critical care medicine & & $86(4.00)$ & $86(3.97)$ \\
\hline Radiology & $2(11.76)$ & $176(8.19)$ & $178(8.22)$ \\
\hline General surgery & $1(5.88)$ & $340(15.83)$ & $341(15.75)$ \\
\hline Thoracic & & $41(1.91)$ & $41(1.89)$ \\
\hline Transplant & & $78(3.63)$ & $78(3.60)$ \\
\hline Urology & & $251(11.69)$ & $251(11.59)$ \\
\hline
\end{tabular}

with COVID-19 incidence, decreasing from $15 \%$ to $8.1 \%$ during the study period. ${ }^{10}$ Despite low incidence of asymptomatic positive cases, our organization continued the preprocedural screening program due to informal feedback indicating proceduralist buy-in, enhanced sense of safety, and improved throughput.
Although universal COVID-19 screening might be ideal, this approach may have unintended consequences. For organizations with high surgical volumes, universal screening may increase costs and cause scheduling challenges, and it will likely put additional strain on testing resources for the hospital. 
Therefore, organizations should consider whether universal screening will produce a high enough yield to offset economic and logistical consequences.

This study had limitations related to generalizability and data analysis. It was conducted at an academic health center in Indiana, and the generalizability of these results to other settings and states with higher incidence may be limited. For example, when this study was conducted, Indiana was on the lower end of case rate per $100,000(1,611)$ compared to states with higher rates such as Louisiana $(3,431)$ and Florida $(3,114){ }^{1}$ In addition, the data analysis focus was descriptive, thus limiting conclusions about relationships and causality or the effects of this program on healthcare worker safety.

Our study validated the value of the preprocedural screening program in allowing the resumption of elective surgical procedures. It was further strengthened through procedural team adoption and sustainment. These findings may help inform decision making of like organizations attempting to enhance safety while resuming elective procedures.

Acknowledgments. The authors thank Nikki Walke, Administrative Director for Perioperative Services, for her contribution to the conception of the preprocedural screening program and support with implementation.

Financial support. No financial support was provided for this study.

Conflicts of interest. All authors report no conflicts of interest relevant to this article.

\section{References}

1. COVID data tracker. Centers for Disease Control and Prevention website. https://covid.cdc.gov/covid-data-tracker/\#cases. Published 2020. Accessed September 3, 2020.
2. COVID-19: guidance for triage of nonemergent surgical procedures. American College of Surgeons website. https://www.facs.org/covid-19/ clinical-guidance/triage. Published 2020. Accessed May 20, 2020.

3. Joint statement: roadmap for resuming elective surgery after COVID-19 pandemic. American College of Surgeons website. https://www.facs.org/ covid-19/clinical-guidance/roadmap-elective-surgery. Published 2020. Accessed September 17, 2020.

4. CMS releases recommendations on adult elective surgeries, nonessential medical, surgical, and dental procedures during COVID-19 response. Centers for Medicare and Medicaid Services website. https://www.cms.gov/ newsroom/press-releases/cms-releases-recommendations-adult-electivesurgeries-non-essential-medical-surgical-and-dental. Published 2020. Accessed September 17, 2020.

5. Chapter 8: Learning from SARS: Renewal of public health in Canada-clinical and public health systems issues arising from the outbreak of SARS in Toronto. Government of Canada website. https://www.canada.ca/en/publichealth/services/reports-publications/learning-sars-renewal-public-healthcanada/chapter-8-clinical-public-health-systems-issues-arising-outbreaksars-toronto.html\#s8c4. Published 2004. Accessed January 28, 2021.

6. Schull MJ, Stukel TA, Vermeulen MJ, et al. Effect of widespread restrictions on the use of hospital services during an outbreak of severe acute respiratory syndrome. CMAJ 2007;176:1827-1832.

7. Symptoms of coronavirus (COVID-19). Centers for Disease Control and Prevention website. https://www.cdc.gov/coronavirus/2019-ncov/downloads/ COVID19-symptoms.pdf. Published 2020. Accessed January 28, 2021.

8. Panesar K, Dodson T, Lynch J, Bryson-Cahn C, Chew L, Dillon J. Evolution of COVID-19 guidelines for University of Washington oral and maxillofacial surgery patient care. J Oral Maxillofac Surg 2020;78:1136-1146.

9. COVID-19: What proportion are asymptomatic? Center for EvidenceBased Medicine University of Oxford website. https://www.cebm.net/ covid-19/covid-19-what-proportion-are-asymptomatic/. Published 2020. Accessed May 20, 2020.

10. 2019 novel coronavirus (COVID-19). Indiana state government website. https://www.coronavirus.in.gov/. Published 2020. Accessed October 15, 2020.

\title{
Mask mandates in light of DANMASK-19
}

\author{
Sajith Matthews MD \\ Division of General Medicine, Department of Internal Medicine, Wayne State University, Detroit, Michigan
}

To the Editor-When public pressure mounted for the use of hydroxychloroquine (HCQ) for prophylaxis or treatment of coronavirus disease 2019 (COVID-19), our nation's leading scientists exercised prudence and recommended awaiting the results of randomized controlled trials (RCTs) before considering its use. Such restraint proved to be invaluable because evidence from these RCTs ultimately showed that there is no benefit but rather harm with HCQ use in the treatment of COVID- 19., ${ }^{1,2}$ A similar focus on high-quality evidence has not been taken for masks and effect on mitigating the spread of disease. Internationally, public health

Author for correspondence: Sajith Matthews, E-mail: smatthew@med.wayne.edu Cite this article: Matthews S. (2022). Mask mandates in light of DANMASK-19. Infection Control \& Hospital Epidemiology, 43: 548-549, https://doi.org/10.1017/ ice. 2021.35 mandates for masks in the community, has varied from no masks to mandatory masks when outside in crowds to wearing masks when symptomatic. ${ }^{3-5}$ Acknowledging the lack of evidence from RCTs of masks having any additive effects on mitigating the transmission of severe acute respiratory syndrome coronavirus 2 (SARS-CoV-2), ${ }^{5}$ public mask use was recommended by the Center for Disease Control (CDC) for protective effect (among healthy individuals) and not just source control (among symptomatic individuals).

The DANMASK-19 was a well-powered randomized controlled trial (6,000 participants) with $46 \%$ proper and $47 \%$ predominantly proper adherence to mask use in a setting of uncommon mask use, moderate spread of infection, and reasonable adherence to social distancing and handwashing. ${ }^{6}$ The DANMASK-19 trial was consistent with the 12 previous $\mathrm{RCTs}^{7}$ which showed, with

( ) The Author(s), 2021. Published by Cambridge University Press on behalf of The Society for Healthcare Epidemiology of America. This is an Open Access article, distributed under the terms of the Creative Commons Attribution licence (http://creativecommons.org/licenses/by/4.0/), which permits unrestricted re-use, distribution, and reproduction in any medium, provided the original work is properly cited. 